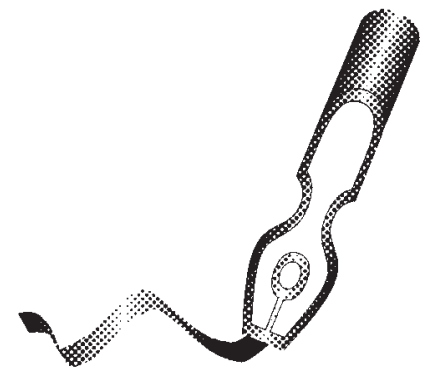

\title{
Otorrinolaringología multidisciplinaria
}

Es habitual que en Otorrinolaringología y Cirugía de Cabeza y Cuello trabajemos en conjunto con médicos de otras especialidades. Por ejemplo, para el manejo de patologías de cavidades paranasales que afectan al globo ocular 0 a la base del cráneo, es frecuente manejar a los pacientes en conjunto con oftalmología y neurocirugía, o en el caso de una patología vestibular central formar equipos con neurología y psiquiatría. También, a menudo abordamos una patología cérvico-facial junto con cirugía plástica y máxilo-facial. Del mismo modo, comúnmente trabajamos con especialistas en foniatría, audiología, enfermería, tecnología médica, psicología, kinesiología, así como con los servicios dentales entre otros profesionales de la salud. Esta labor en equipos multidisciplinarios genera beneficios para el manejo clínico de los pacientes y contribuye al desarrollo técnico de los profesionales involucrados. Adicionalmente, el trabajo multidisciplinario amplía el campo de la investigación e innovación en nuestra disciplina. Es importante que los hospitales, clínicas y universidades fomenten activamente la conformación y consolidación de equipos multidisciplinarios.

Además de este trabajo multidisciplinario en salud, en el idioma inglés se ha acuñado el término "transdisciplinary", que podría ser traducido a transdisciplinario, aunque la Real Academia Española aún no incluye este término en su diccionario, pero sí el prefijo "trans", que significa "al otro lado de" o "a través de". Un equipo transdisciplinario, además de especialistas en medicina, incorpora a profesionales e investigadores que se desempeñan fuera de las disciplinas de la salud. Un ejemplo es el desarrollo con ingenieros de nuevos dispositivos para el diagnóstico y tratamiento de la sordera. Otro se observa en la planificación con arquitectos de hogares para pacientes de edad avanzada que tienen trastornos del equilibrio y riesgo de caídas, o en la generación de nuevos marcos regulatorios, junto a abogados, para proteger a trabajadores expuestos a tóxicos u otros elementos asociados al desarrollo de patologías sensoriales o tumorales. Estos casos nos ilustran sobre como el trabajo transdisciplinario puede provocar cambios importantes en las personas y la sociedad.

En el presente número de la revista, destaco los artículos de revisión de Álvarez y Villamor sobre complicaciones en traqueostomía en niños y el artículo de Rosenbaum y cols., que revisa el tema de la vacuna contra el virus papiloma humano en la papilomatosis recurrente de la vía aérea. También quiero resaltar el estudio de Cortés y cols., quienes realizaron un trabajo multidisciplinario estandarizando el proceso de decanulación de los pacientes traqueostomizados del Hospital Carlos 
van Buren de Valparaíso. De igual modo, el artículo de Novoa y cols., trabajaron en forma multidisciplinaria para demostrar la efectividad de la terapia de rehabilitación vestibular en mujeres mayores de 60 años.

Al igual que los artículos de Cortés y cols. y de Novoa y cols., en nuestra revista queremos seguir recibiendo estudios multidisciplinarios, pero también los convoco a romper las barreras de la medicina, ir más allá e interactuar con otras disciplinas, a fin de conformar equipos de investigación transdisciplinarios para generar soluciones innovadoras, incorporando los puntos de vista diversos que aportan los profesionales externos al área de la salud. Sin duda que proseguir el trabajo multidisciplinario y sumar la perspectiva transdisciplinaria permitirá elevar los estándares de salud de la población. Como director de la revista, espero recibir también trabajos de investigación transdisciplinaria donde la otorrinolaringología dialogue con disciplinas como ingeniería, antropología, música, arquitectura y economía, entre otras.

Dr. Paul Délano Reyes

Departamento de Otorrinolaringología,

Facultad de Medicina, Universidad de Chile 